\title{
The prevalence of visually significant cataract in the Australian National Eye Health Survey
}

\author{
Stuart Keel ${ }^{1,2} \cdot$ Myra B. McGuiness $\mathbb{1}^{1,2} \cdot$ Joshua Foreman ${ }^{1,2} \cdot$ Hugh R. Taylor $^{3} \cdot$ Mohamed Dirani $^{1,4}$
}

Received: 10 May 2018 / Revised: 29 October 2018 / Accepted: 18 November 2018 / Published online: 12 February 2019

(c) The Royal College of Ophthalmologists 2019

\begin{abstract}
Purpose To describe the prevalence of visually significant cataract in Indigenous and non-Indigenous Australians. Methods A total of 3098 non-Indigenous Australians aged 50 years and over and 1738 Indigenous Australians aged 40 years and over, residing in 30 randomly selected Australian sites, were examined as part of the population-based National Eye Health Survey (NEHS). For those with visual acuity worse than 6/12, photos of the anterior and posterior segment were taken with a nonmydriatic fundus camera and assessed for cataract. Visually significant cataract was assigned in eyes with best-corrected visual acuity worse than $6 / 12$ and cataract that was determined to be the primary cause of vision loss in that eye.

Results In total, 99.2\% (4797/4836) participants had complete data for visual acuity and cataract assessment. The overall weighted prevalence of visually significant cataract was $2.7 \%$ (95\% CI: 2.0, 3.5) in non-Indigenous Australians and $4.3 \%$ (95\% CI: 3.1, 5.9) among Indigenous Australians. After adjusting for age and gender, the odds of visually significant cataract were almost three times higher among Indigenous participants compared to non-Indigenous participants (adjusted odds ratio (OR) $2.95,95 \%$ CI: $2.03,4.29$ ). Only $54.8 \%$ of non-Indigenous Australians and $38.9 \%$ of Indigenous Australians with visually significant cataract self-reported a known history of cataract.

Conclusions Our results suggest that continued efforts are required to build sustainable cataract surgery services within Indigenous communities. Furthermore, given the significant ageing of the Australian population, maintaining high cataract surgery rates amongst the non-Indigenous population is critical to reduce cataract-related vision loss.
\end{abstract}

Supplementary information The online version of this article (https:// doi.org/10.1038/s41433-019-0354-x) contains supplementary material, which is available to authorized users.

$\triangle$ Stuart Keel

stuart.keel@unimelb.edu.au

1 Centre for Eye Research Australia, Royal Victorian Eye \& Ear Hospital, Melbourne, VIC, Australia

2 Department of Surgery, Ophthalmology, University of Melbourne, Melbourne, VIC, Australia

3 Indigenous Eye Health Unit, Melbourne School of Population and Global Health, University of Melbourne, Melbourne, VIC, Australia

4 Singapore Eye Research Institute, Singapore National Eye Centre, Singapore, Singapore

\section{Introduction}

Cataract is a leading cause of treatable vision loss globally [1] and in Australia [2]. Not only do individuals with visually significant cataract experience a deterioration of visual acuity, they often experience a loss of contrast sensitivity, difficulties with glare, and altered colour recognition [3, 4]. With an ageing Australian population, a significant increase in the burden of cataract is projected [5]. Thus, to assist in informing the appropriate planning for eye health care delivery, it is important to quantify Australia's burden of visually significant cataract. Furthermore, an improved understanding of the prevalence of undiagnosed visually significant cataract may help inform more targeted public health strategies to increase eye health awareness.

To date, most previous population-based studies report the prevalence and risk factors of any cataract [6-9], with only few documenting the burden of visually significant cataract $[10,11]$. Internationally, the reported prevalence of visually significant cataract ranges from $1.9 \%$ in the Los 
Angeles Latino Eye Study (LALES) [11] to $10.6 \%$ in the Singapore Malay Eye Study [10]. In Australia, two population-based cohort studies conducted in the early 1990s comprehensively reported the prevalence, incidence, and risk factors of any cataract amongst the non-Indigenous population $[12,13]$. Since their completion, there have been substantial demographic changes and neither study reported epidemiological data on the prevalence of visually significant cataract. Amongst the Indigenous population, the National Indigenous Eye Health Survey (NIEHS, 2008) reported the national prevalence of bilateral visually significant cataract to be $2.5 \%$ [14], while the Central Australian Ocular Health Study (CAOHS, 2010) conducted within remote central Australia reported the prevalence of any (i.e., bilateral and unilateral) visually significant cataract to be in excess of 17\% [15]. Given that prevalence of cataract have been reported to be higher in Indigenous communities and the accessibility to cataract surgery services differs considerably across remoteness areas of Australia, careful monitoring of the prevalence of visually significant cataract is required.

The purpose of this study was to estimate the prevalence of visually significant cataract in non-Indigenous and Indigenous Australian adults, stratified by geographic remoteness, as part of the National Eye Health Survey (NEHS).

\section{Methods}

\section{Study population}

The NEHS (March 2015 to April 2016) is a nationwide population-based survey that investigated the prevalence and causes of vision loss $(<6 / 12)$ among non-Indigenous Australians aged 50 years and older and Indigenous Australians aged 40 years and older. The younger age criterion was chosen for Indigenous participants due to the earlier onset and more rapid progression of common eye diseases in that population [16]. The sampling and testing methodology has been described in detail elsewhere [17, 18]. In brief, the sample size calculation assumed a similar prevalence of vision loss to historical population-based data for non-Indigenous and Indigenous Australians [19, 20]. Assuming a margin of error of $1.1 \%$ for non-Indigenous Australians and 2\% for Indigenous Australians, a design effect of 1.5 that adjusted for interclass correlations and a $20 \%$ nonresponse rate, the required sample size for the nonIndigenous and Indigenous populations was approximately 3000 and 1500, respectively. Multistage random-cluster sampling was used to select 30 population clusters of 150 participants (100 non-Indigenous and 50 Indigenous per sampling site). Selection of sites utilised Census 2011 data collected by the Australian Bureau of Statistics (ABS) that categorised Statistical Areas into five Remoteness Areas (RAs); Major City, Inner Regional, Outer Regional, Remote, and Very Remote. Participants were recruited door to door and the overall population positive response rate was $71.5 \%$ (4836/6760). Ethics approval was obtained from the Royal Victorian Eye and Ear Hospital (RVEEH) Human Research Ethics Committee (HREC-14/1199H) and additional ethical approvals were obtained at the State level to conduct research within Indigenous communities. Study procedures adhered to the tenets of the Declaration of Helsinki as revised in 2013 and participants provided written informed consent to participate.

\section{Procedures}

Sociodemographic data, utilisation of eye health services, as well as stroke, diabetes, and ocular history data were collected via an interviewer-administered questionnaire. Participants self-reported whether they had previously undergone cataract surgery in the right and/or left eye. Presenting distance visual acuity (PVA) was measured in each eye using a $\log$ MAR chart (Brien Holden Vision Institute, Sydney, Australia) in well-lit room conditions. Pinhole testing was performed on participants with vision loss (PVA < 6/12) in one or both eyes, followed by automated refraction (Nidek ARK-30, Nidek Co., LTD, Japan) if pinhole visual acuity improved to $\geq 6 / 12$ in either eye. Best-corrected visual acuity (BCVA) was defined as the best of the pinhole or automated refraction measurements for each eye. Examination of the anterior segment was performed using a hand-held slit-lamp (Keeler Ophthalmic Instruments, UK). Participants with PVA $<6 / 12$ in one or both eyes had anterior segment photographs taken using a Digital Retinography System (DRS) camera (CenterVue SpA, Italy). Two-field, $45^{\circ}$ colour fundus photographs were taken of each retina, centred on the macula and optic disc, respectively, with the DRS camera in a darkened room to allow for physiological mydriasis. Trained retinal graders from the Centre for Eye Research Australia masked to the identity and clinical characteristics of study participants graded fundus photographs for retinal disease.

\section{Diagnosis of visually significant cataract}

Visually significant cataract was defined as any eye with BCVA of $<6 / 12$ and cataract as the primary cause of vision loss in that eye. This definition is in line with previous Australian [14, 15] and international reports [10, 11] and was adopted as $6 / 12$ is a legal requirement for driving in Australia and therefore these cases should be prioritised for targeted resource allocation. To ensure an accurate diagnosis of visually significant cataract, a two-step protocol was utilised. First, two optometrists independently assessed 
anterior segment photographs and fundus photographs to categorise participants into one of three groups: (1) no cataract, (2) probable cataract, or (3) definite cataract. High inter-rater reliability (85\%) and intra-rater reliability (94 and $96 \%$ ) were achieved. Any discrepancies were adjudicated by an ophthalmologist. In cases where photographs were unavailable, a cataract grade was assigned on the basis of an anterior segment examination by a trained clinician using a hand-held slit-lamp (Keeler Ophthalmic Instruments, UK). Second, a single ophthalmologist reviewed relevant case notes (retinal and anterior photographs, grading data and clinical examination results) of all participants with bestcorrected VA of $<6 / 12$ in one or both eyes, and assigned the main cause of unilateral or bilateral vision loss. Participants with visual impairment for whom the cause of vision loss was not determinable and were not pseudophakic were excluded from the analyses.

\section{Statistical analysis}

Differences between included and excluded participants were compared using a chi-squared test or Wilcoxon test for categorical and continuous variables, respectively. The $95 \%$ confidence interval (CI) for crude prevalence was estimated using robust standard errors to account for clustering within study site. Population proportions were estimated using post-stratification for age in addition to the survey weights which were derived separately for Indigenous and nonIndigenous participants according to study site. Population values were derived using data from the 2016 Australian Census (source: Australian Bureau of Statistics TableBuilder www.abs.gov.au, accessed 19 April 2018).

Age- and sex-adjusted logistic regression was performed separately for Indigenous and non-Indigenous participants to investigate the following risk factors for visually significant cataract: educational attainment, language, place of birth (for non-Indigenous participants only), remoteness area, self-reported diabetes, and time since last eye exam. Robust standard errors were used to account for clustering within study site. All analyses were performed using Stata/ SE version 15.1 (StataCorp LP, College Station, TX, USA).

\section{Results}

To explore potential response bias, we compared sociodemographic characteristics (age, gender, education status, and country of birth) of NEHS participants to the target population using Australian Census 2016 data. The Indigenous sample in the NEHS had a lower proportion of males, people in the youngest age group (40-49 years), and an overall lower level of educational attainment when compared to those in the target Australian population
( $p<0.001$ for each). Non-Indigenous participants in the NEHS were less likely to be born outside of Oceania or Europe, had an overall lower educational attainment, and there was a lower proportion of people in the youngest age group (50-59 years) when compared to those in the target population ( $p<0.001$ for each).

A total of 4836 individuals were recruited and examined in the NEHS, including 3098 non-Indigenous and 1738 Indigenous Australians. Of these, 1211 (25\%) participants had vision loss in at least one eye. The cause of vision loss could not be ascertained in 39 phakic participants $(3.2 \%)$, leaving a total of $4797(99.2 \%)$ participants eligible for inclusion. This included 3079 non-Indigenous $(53.7 \%$ female, median age (interquartile range (IQR)) 66.2 (59.6-73.5) years) and 1718 Indigenous (59.0\% female, median age (IQR) 54.2 (47.5-61.8) years) Australians. There were no differences in the distribution of gender $(p=0.39)$ and remoteness $(p=0.41)$ amongst participants who were and were not excluded. However, on average, excluded participants were older $(p=0.04)$ and more likely to be Indigenous $(p=0.045)$.

\section{Weighted prevalence of visually significant cataract by Indigenous status}

In the non-Indigenous population aged 50 years and over, the weighted prevalence of visually significant cataract was 2.7\% (95\% CI: 2.0, 3.5) (Table 1). Among Indigenous Australians aged 40 years and over, the weighted prevalence of visually significant cataract was $4.3 \%$ (95\% CI: $3.1,5.9)$. Bilateral visually significant cataract was present in 29 non-Indigenous participants and 43 Indigenous participants. The weighted prevalence of visually significant cataract increased with age in non-Indigenous participants, with the following age-specific prevalence: $0.9 \%$ in those $<60$ years, $2.5 \%$ in those aged 60-69 years, $4.8 \%$ in those aged 70-79 years, and 5.0\% in those aged 80-99 years. In the Indigenous population, the prevalence of visually significant cataract for the age groups of $<60$ years, 60-69 years, 70-79 years, and 80-99 years were 1.9\%, 7.0\%, $12.8 \%$, and $34.1 \%$, respectively. Visually significant cataract was found in $3.2 \%$ of males and $2.2 \%$ of females in the non-Indigenous population. Among Indigenous Australians aged 40 years and over, the prevalence of visually significant cataract was $3.7 \%$ for males and $4.6 \%$ for females.

\section{Associations of visually significant cataract}

After adjusting for age and gender, the odds of visually significant cataract were almost three times higher among Indigenous participants compared to non-Indigenous participants (adjusted odds ratio (OR) 2.95, 95\% CI: 2.03, 4.29). 
Table 1 Crude and estimated population prevalence of visually significant cataract for Indigenous Australians 40 years of age and above and nonIndigenous Australians 50 years of age and above, National Eye Health Survey $(n=4797,2015$ 2016)

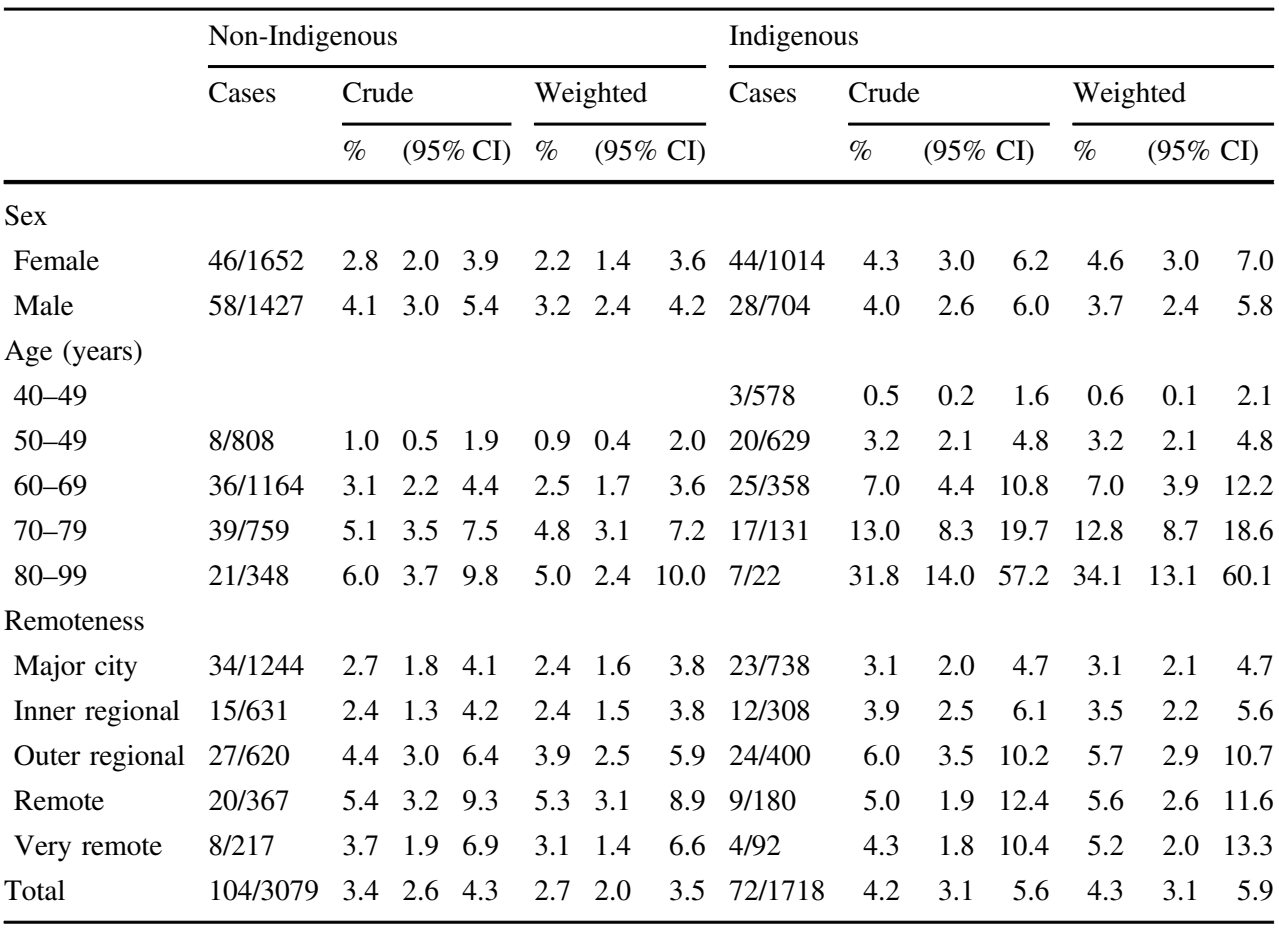

Sampling weights were derived according to study site separately for Indigenous and non-Indigenous Australians. Population prevalence was estimated using post-stratification for age group in addition to sampling weights

$C I$ confidence interval
In the non-Indigenous population, adjusted logistic regression analysis revealed that increasing age, male gender, and fewer years of education were associated with visually significant cataract. Among Indigenous participants, increasing age, speaking a language other than English, and having never had an eye examination were associated with higher odds of visually significant cataracts (Table 2). All significant associations of visually significant cataract remained in the fully adjusted model (Supplementary Table 1).

\section{Undiagnosed visually significant cataract}

In the non-Indigenous population, 54.8\% (57/104) of all visually significant cataract cases self-reported a history of being previously diagnosed with cataract. Of all undiagnosed cases in the non-Indigenous population, only $28.3 \%$ (13/46) had accessed an optometry or ophthalmology service in the past 12 months (self-report). Among the Indigenous population, $38.9 \%$ (28/72) of cases with visually significant cataract self-reported a history or being previously diagnosed with cataract. Of all undiagnosed cases, $34.4 \%$ (11/32) had accessed an optometry or ophthalmology service in the past 12 months (self-report). The presence of undiagnosed visually significant cataract was associated with older age and longer time since last eye exam in the non-Indigenous population, and older age and speaking a language other than English in the Indigenous population (Table 3 ).

\section{Discussion}

This paper presents the prevalence of visually significant cataract in a population-based, national sample of nonIndigenous and Indigenous Australian adults. After adjusting for age, the odds of visually significant cataract were almost 3 times higher in Indigenous Australians compared to nonIndigenous Australians. The prevalence of visually significant cataract rose sharply with age, with Indigenous and non-Indigenous persons aged 70-79 years being approximately 4 times more likely to have visually significant cataract than persons aged under 50-59 years of age.

The prevalence of visually significant cataract in nonIndigenous Australians in the NEHS (2.7\%) is similar to that reported in the LALES (1.9\%) [11] and is low by comparison to other population-based reports from developed nations [1, 10]. The relatively low prevalence observed in non-Indigenous Australians is perhaps not surprising given cataract surgery is the most commonly performed elective surgical procedure in Australia and is subsidised by government funding [21]. Furthermore, this finding is in line with our previous work that reports accessibility and utilisation rates of cataract surgery services 
Table 2 Estimated association between participant characteristics and visually significant cataract in the National Eye Health Survey, 2015$2016(n=4797)$

\begin{tabular}{|c|c|c|c|c|}
\hline & \multicolumn{2}{|c|}{ Non-Indigenous } & \multicolumn{2}{|c|}{ Indigenous } \\
\hline & OR & $(95 \% \mathrm{CI})$ & OR & $(95 \% \mathrm{CI})$ \\
\hline \multicolumn{5}{|l|}{ Sex } \\
\hline Female & Ref & & Ref & \\
\hline Male & 1.45 & $(1.02,2.08)$ & 0.89 & $(0.53,1.50)$ \\
\hline \multicolumn{5}{|l|}{ Age (years) } \\
\hline $40-49$ & NA & & Ref & \\
\hline $50-59$ & Ref & & 6.33 & $(1.82,21.94)$ \\
\hline $60-69$ & 3.15 & $(1.54,6.43)$ & 14.4 & $(4.39,47.19)$ \\
\hline $70-79$ & 5.38 & $\begin{array}{l}(2.57 \\
11.23)\end{array}$ & 28.84 & $(7.43,112.00)$ \\
\hline $80-99$ & 6.34 & $\begin{array}{l}\text { (2.99, } \\
13.43)\end{array}$ & 88.84 & $\begin{array}{l}\text { (16.55, } \\
\text { 477.05) }\end{array}$ \\
\hline \multicolumn{5}{|l|}{ Residence } \\
\hline Major city & Ref & & Ref & \\
\hline Inner regional & 0.79 & $(0.39,1.59)$ & 1.06 & $(0.53,2.14)$ \\
\hline Outer regional & 1.54 & $(0.89,2.66)$ & 1.99 & $(0.92,4.29)$ \\
\hline Remote & 2.01 & $(0.98,4.13)$ & 1.66 & $(0.65,4.20)$ \\
\hline Very remote & 1.34 & $(0.71,2.50)$ & 1.31 & $(0.39,4.39)$ \\
\hline \multicolumn{5}{|l|}{ Education } \\
\hline Less than high school & Ref & & Ref & \\
\hline Completed high school & 0.59 & $(0.30,1.16)$ & 1.91 & $(0.88,4.13)$ \\
\hline $\begin{array}{l}\text { Completed trade or university } \\
\text { qualification }\end{array}$ & 0.46 & $(0.24,0.87)$ & 0.47 & $(0.21,1.07)$ \\
\hline \multicolumn{5}{|l|}{ Main language spoken at home } \\
\hline English & Ref & & Ref & \\
\hline Language other than English & 1.67 & $(0.78,3.56)$ & 2.37 & $(1.01,5.56)$ \\
\hline \multicolumn{5}{|l|}{ Self-reported diabetes } \\
\hline No & Ref & & Ref & \\
\hline Yes & 1.29 & $(0.76,2.18)$ & 1.72 & $(0.93,3.16)$ \\
\hline \multicolumn{5}{|l|}{ Time of last eye exam } \\
\hline Less than 1 year & Ref & & Ref & \\
\hline Between 1 and 2 years & 0.77 & $(0.45,1.33)$ & 0.72 & $(0.36,1.44)$ \\
\hline Greater than 2 years & 1.66 & $(0.76,3.61)$ & 0.80 & $(0.42,1.51)$ \\
\hline Never & 1.02 & $(0.12,8.62)$ & 2.78 & $(1.39,5.55)$ \\
\hline \multicolumn{5}{|l|}{ Ethnicity } \\
\hline Oceanian & Ref & & NA & \\
\hline European & 1.19 & $(0.78,1.81)$ & & \\
\hline Other & 1.29 & $(0.47,3.57)$ & & \\
\hline
\end{tabular}

ORs estimated via logistic regression, adjusting for age and sex

$C I$ confidence interval, $O R$ odds ratio, Ref reference value, $N A$ not available

Bold means $p=<0.05$

[22] and eye health care services in general [23] are high amongst the non-Indigenous Australian population. Nonetheless, our finding of a significantly higher prevalence of visually significant cataract amongst non-Indigenous males in the NEHS is noteworthy. This observed difference appears to be partly attributable to a less frequent utilisation of eye care services (previous examination $>2$ years ago or never; males $=20.8 \%$ vs. females $=12.0 \%$ ) and a higher prevalence of self-reported diabetes (males $=16.8 \%$ vs. $11.3 \%$ ) amongst non-Indigenous men in the NEHS, placing
Table 3 Fully adjusted model examining associations between participant characteristics and undiagnosed visually significant cataract in the National Eye Health Survey, 2015-2016 $(n=4797)$

\begin{tabular}{|c|c|c|c|c|}
\hline & \multicolumn{2}{|c|}{ Non-Indigenous } & \multicolumn{2}{|c|}{ Indigenous } \\
\hline & OR & $(95 \% \mathrm{CI})$ & OR & $(95 \% \mathrm{CI})$ \\
\hline \multicolumn{5}{|l|}{ Sex } \\
\hline Female & Ref & & Ref & \\
\hline Male & 1.00 & $(0.53,1.90)$ & 0.94 & $(0.51,1.74)$ \\
\hline \multicolumn{5}{|l|}{ Age (years) } \\
\hline $40-49$ & NA & & Ref & \\
\hline $50-59$ & Ref & & 5.72 & $(1.04,31.43)$ \\
\hline $60-69$ & 2.07 & $(0.67,6.39)$ & 7.93 & $(1.58,39.79)$ \\
\hline $70-79$ & 2.87 & $(1.04,7.90)$ & 17.23 & $\begin{array}{l}(2.35, \\
126.50)\end{array}$ \\
\hline $80-99$ & 4.29 & $\begin{array}{l}(1.30 \\
14.16)\end{array}$ & 57.65 & $\begin{array}{l}(5.14, \\
646.90)\end{array}$ \\
\hline \multicolumn{5}{|l|}{ Residence } \\
\hline Major city & Ref & & Ref & \\
\hline Inner regional & 0.53 & $(0.23,1.22)$ & 1.00 & $(0.40,2.50)$ \\
\hline Outer regional & 0.56 & $(0.27,1.20)$ & 1.53 & $(0.51,4.62)$ \\
\hline Remote & 1.63 & $(0.70,3.81)$ & 1.50 & $(0.46,4.89)$ \\
\hline Very remote & 0.46 & $(0.23,0.94)$ & 0.57 & $(0.11,3.04)$ \\
\hline \multicolumn{5}{|l|}{ Education } \\
\hline Less than high school & Ref & & Ref & \\
\hline Completed high school & 1.30 & $(0.51,3.34)$ & 2.09 & $(0.54,8.12)$ \\
\hline $\begin{array}{l}\text { Completed trade or university } \\
\text { qualification }\end{array}$ & 0.57 & $(0.26,1.24)$ & 0.74 & $(0.29,1.92)$ \\
\hline \multicolumn{5}{|l|}{ Main language spoken at home } \\
\hline English & Ref & & Ref & \\
\hline Language other than English & 0.59 & $(0.10,3.39)$ & 3.53 & $(1.60,7.81)$ \\
\hline \multicolumn{5}{|l|}{ Self-reported diabetes } \\
\hline No & Ref & & Ref & \\
\hline Yes & 1.25 & $(0.51,3.06)$ & 1.12 & $(0.49,2.55)$ \\
\hline \multicolumn{5}{|l|}{ Time of last eye exam } \\
\hline Less than 1 year & Ref & & Ref & \\
\hline Between 1 and 2 years & 1.28 & $(0.56,2.96)$ & 0.71 & $(0.28,1.82)$ \\
\hline Greater than 2 years & 5.12 & $\begin{array}{l}(1.91 \\
13.70)\end{array}$ & 1.30 & $(0.58,2.91)$ \\
\hline Never & 4.48 & $\begin{array}{l}(0.55 \\
36.27)\end{array}$ & 1.86 & $(0.53,6.49)$ \\
\hline \multicolumn{5}{|l|}{ Ethnicity } \\
\hline Oceanian & Ref & & NA & \\
\hline European & 0.97 & $(0.46,2.05)$ & & \\
\hline Other & 1.14 & $(0.23,5.79)$ & & \\
\hline
\end{tabular}

ORs estimated via logistic regression, adjusting for all variables listed in the table

$C I$ confidence interval, $O R$ odds ratio, Ref reference value, NA not available

Bold means $p=<0.05$

them at a higher risk of vision loss from cataract. It may also be speculated that a known higher exposure to modifiable cataract-related risk factors, including ultraviolet-B exposure [24] and smoking [25], amongst Australian males may contribute to this gender difference.

In line with previous international reports [26-28], lower educational attainment was associated with greater risk of visually significant cataract amongst non-Indigenous 
Australians in the NEHS. Educational attainment is an important surrogate of socioeconomic status [29], and therefore this finding may reflect the role of poorer lifestyle choices (e.g., smoking), a lower health literacy, or real or perceived costs of cataract surgery amongst non-Indigenous Australians with lower levels of education. Given Australia has a universal health insurance scheme (i.e. Medicare) and the availability of ophthalmology clinics in public hospitals, our results provide evidence that targeted eye health promotion may be warranted to improve awareness and eye health literacy.

Previous research has inferred a disproportionately higher prevalence of visually significant cataract [14, 15, 30], and longer wait times for cataract surgery, amongst Indigenous Australians [31, 32]. As such, over the past decade, several targeted interventions have been implemented to improve the accessibility of cataract surgery services and reduce the burden of visually significant cataract in this population [33]. To allow for more robust comparisons with the CAOHS, the weighted prevalence of cataract in the Indigenous population was recalculated to include those residing in remote and very remote areas only. After adjustments, the prevalence was notably lower than the CAOHS (CAOHS $=17 \%$ vs. $\mathrm{NEHS}=5.3 \%$ ). We speculate that the observed differences are, at least in part, explained by contrasting regions of Australia that were sampled. That is, the CAOHS recruited participants from inland regions only, where greater barriers (e.g., increased travel distance) to accessing cataract surgery services exist [34]. We report a prevalence of bilateral visually significant cataract that is comparable with that of the NIEHS $(2.5 \%)$ [14]. However, as cataract is strongly age-related and Indigenous participants in the NEHS were, on average, older (mean age; NEHS $=58$ years vs. NIEHS $=50$ years) than NIEHS participants, this finding may in fact reflect a modest improvement in the prevalence of visually significant cataract in the ageing Indigenous population [35]. Nonetheless, our finding that the age-adjusted weighted prevalence of visually significant cataract was almost 3 times higher $(\mathrm{OR}=2.95)$ in Indigenous Australians than non-Indigenous Australians highlights that continued efforts are required to build sustainable cataract surgery services within Indigenous communities.

Very few population-based studies have investigated the prevalence of undiagnosed visually significant cataract $[10,11]$. In the present study, approximately $60 \%$ of Indigenous Australians and $45 \%$ of non-Indigenous Australians with visually significant cataract did not have a known history of cataract. The frequency of undiagnosed visually significant cataract in Indigenous Australians is similar to that reported in the Singapore Malay Eye Study $(70 \%)$ and the LALES $(60 \%)[10,11]$. It is plausible that the high undiagnosed rates in the present study are attributable to the fact that most cases of age-related cataract are slow progressing, and therefore gradual changes in visual acuity go unnoticed. In addition, approximately $70 \%$ of non-indigenous and Indigenous Australians with undiagnosed visually significant cataract had not accessed an optometry or ophthalmology service in the past 12 months. These results emphasise that improved awareness of the importance of regular eye examinations is warranted, particularly given vision loss from cataract is readily treatable.

Unlike findings from the NIEHS (2008) [14], our results suggest that Indigenous Australians who do not speak English as their primary language at home are at a notably higher risk of visually significant cataract (including undiagnosed). Given an estimated $11 \%$ of Indigenous Australians speak an Indigenous language at home [36], this finding reinforces the importance of understanding linguistic and cultural backgrounds when planning eye health services, and providing access to Indigenous language interpreter services for clinical discussions.

The strengths of this study include its sampling design, stratification by Indigenous status, and the large sample size. Some limitations must also be considered. Firstly, we did not utilise a traditional slit-lamp grading method (e.g., Wisconsin cataract grading system, Lens Opacities Classification System, The Age-Related Eye Disease Study System) to diagnose cataract, rather we adopted a less common method using a nonmydriatic fundus camera [37]. Nonetheless, a high sensitivity and specificity for detecting visually significant cataract has been demonstrated using this method [37]. Second, prior diagnosis of cataract was obtained via self-report. Therefore, the influence of recall and/or misclassification bias on our analysis of 'undiagnosed' cataract cannot be discounted. Third, a failure to capture several known and potential cataract-related risk factors (ultraviolet-B exposure, smoking, cortico-steroid use, systemic diseases, diet) limited our ability to conduct a more meaningful risk factor analysis. Lastly, sufficient information from all the non-responders was not available to quantify response bias. However, a comparison of key sociodemographic characteristics to the target Australian population revealed that, on average, participants in the NEHS were older and had a lower educational attainment. Given both of these factors were associated with a greater risk of visually significant cataract in the present study, this may have resulted in an overestimation of the true prevalence of cataract. Strategies to address potential response bias included post-survey adjustments of prevalence estimates to the age structure of the nation for both non-Indigenous and Indigenous populations. 
In conclusion, this report described the age-, gender-, and Indigenous-specific prevalence estimates of visually significant cataract in a national population-based sample of Australian adults. Our data suggest that several high-risk groups, including those aged over 70 years, Indigenous Australians who speak a language other than English at home and non-Indigenous males and those with fewer years of education may benefit from targeted eye health awareness campaigns and improvements in the provision of cataract surgery services. With a significant ageing of the Australian population and an increase in life expectancy, high cataract surgery rates are critical to reduce cataractrelated vision loss in Australia.

\section{Summary}

\section{What was known before}

- In Australia, knowledge of the epidemiology of visually significant cataract remains scarce due to a paucity of recent population-based data.

\section{What this study adds}

- The National Eye Health Survey provides an up-to-date estimate of the prevalence of visually significant cataract in non-Indigenous and Indigenous Australian adults.

Acknowledgements The National Eye Health Survey was funded by the Department of Health of the Australian Government, and also received financial contributions from the Peggy and Leslie Cranbourne Foundation and Novartis Australia. The funding organisations played no role in the design and conduct of the study. In-kind support was received from our industry and sector partners, OPSM, Carl Zeiss, Designs for Vision, the Royal Flying Doctor Service, Optometry Australia, and the Brien Holden Vision Institute. We would like to specifically acknowledge OPSM, who kindly donated sunglasses valued at $\$ 130$ for each study participant. The Centre for Eye Research Australia receives Operational Infrastructure Support from the Victorian Government. The Principal Investigator, Dr Mohamed Dirani, is supported by a NHMRC Career Development Fellowship (\#1090466). The PhD student Joshua Foreman is supported by an Australian Postgraduate Award scholarship. The Centre for Eye Research Australia (CERA) and Vision 2020 Australia wish to recognise the contributions of all the NEHS project steering committee members (Professor Hugh Taylor, Dr. Peter van Wijngaarden, Jennifer Gersbeck, Dr. Jason Agostino, Anna Morse, Sharon Bentley, Robyn Weinberg, Christine Black, Genevieve Quilty, Louis Young, and Rhonda Stilling) and the core CERA research team who assisted with the survey field work (Joshua Foreman, Pei Ying Lee, Rosamond Gilden, Larissa Andersen, Benny Phanthakesone, Celestina Pham, Alison Schokman, Megan Jackson, Hiba Wehbe, John Komser, and Cayley Bush). Furthermore, we would like to acknowledge the overwhelming support from all collaborating Indigenous organisations who assisted with the implementation of the survey, and the Indigenous health workers and volunteers in each survey site who contributed to the field work.

\section{Compliance with ethical standards}

Conflict of interest The authors declare that they have no conflict of interest.

Publisher's note: Springer Nature remains neutral with regard to jurisdictional claims in published maps and institutional affiliations.

\section{References}

1. Flaxman SR, Bourne RRA, Resnikoff S, Ackland P, Braithwaite $\mathrm{T}$, Cicinelli MV, et al. Global causes of blindness and distance vision impairment 1990-2020: a systematic review and metaanalysis. Lancet Glob Health. 2017;5:e1221-e34.

2. Foreman J, Keel S, van Wijngaarden P, Bourne RA, Wormald R, Crowston J, et al. Prevalence and Causes of Visual Loss Among the Indigenous Peoples of the World: A Systematic Review. JAMA ophthalmology. 2018.

3. Crabtree HL, Hildreth AJ, O'Connell JE, Phelan PS, Allen D, Gray CS. Measuring visual symptoms in British cataract patients: the cataract symptom scale. Br J Ophthalmol. 1999;83:519-23.

4. Ginsburg AP. Contrast sensitivity: determining the visual quality and function of cataract, intraocular lenses and refractive surgery. Curr Opin Ophthalmol. 2006;17:19-26.

5. Rochtchina E, Mukesh BN, Wang JJ, McCarty CA, Taylor HR, Mitchell P. Projected prevalence of age-related cataract and cataract surgery in Australia for the years 2001 and 2021: pooled data from two population-based surveys. Clin Exp Ophthalmol. 2003;31:233-6.

6. Klein BE, Klein RE, Lee KE. Incident cataract after a five-year interval and lifestyle factors: the Beaver Dam eye study. Ophthalmic Epidemiol. 1999;6:247-55.

7. Navarro Esteban JJ, Gutierrez Leiva JA, Valero Caracena N, Buendia Bermejo J, Calle Puron ME, Martinez Vizcaino VJ. Prevalence and risk factors of lens opacities in the elderly in Cuenca, Spain. Eur J Ophthalmol. 2007;17:29-37.

8. Richter GM, Choudhury F, Torres M, Azen SP, Varma R. Risk factors for incident cortical, nuclear, posterior subcapsular, and mixed lens opacities: the Los Angeles Latino eye study. Ophthalmology. 2012;119:2040-7.

9. Tan JS, Wang JJ, Younan C, Cumming RG, Rochtchina E, Mitchell P. Smoking and the long-term incidence of cataract: the Blue Mountains Eye Study. Ophthalmic Epidemiol. 2008;15:155-61.

10. Chua J, Lim B, Fenwick EK, Gan AT, Tan AG, Lamoureux E, et al. Prevalence, Risk Factors, and Impact of Undiagnosed Visually Significant Cataract: The Singapore Epidemiology of Eye Diseases Study. PLoS One. 2017;12:e0170804.

11. Richter GM, Chung J, Azen SP, Varma R, Los Angeles Latino Eye Study G. Prevalence of visually significant cataract and factors associated with unmet need for cataract surgery: Los Angeles Latino Eye Study. Ophthalmology. 2009;116:2327-35.

12. McCarty CA, Mukesh BN, Dimitrov PN, Taylor HR. Incidence and progression of cataract in the Melbourne Visual Impairment Project. Am J Ophthalmol. 2003;136:10-7.

13. Mitchell P, Cumming RG, Attebo K, Panchapakesan J. Prevalence of cataract in Australia: the Blue Mountains eye study. Ophthalmology. 1997;104:581-8.

14. Taylor HR, Xie J, Arnold AL, Goujon N, Dunn RA, Fox S, et al. Cataract in indigenous Australians: the National Indigenous Eye Health Survey. Clin Experiment Ophthalmol. 2010;38:790-5.

15. Landers J, Henderson T, Craig J. Prevalence and associations of cataract in indigenous Australians within central Australia: the Central Australian Ocular Health Study. Clin Experiment Ophthalmol. 2010;38:387-92. 
16. AIHW. Vision problems among older Australians. Australian Institute of Health and Welfare; 2005. http://www.aihw.gov.au/ WorkArea/DownloadAsset.aspx id $=6442453390$.

17. Foreman J, Keel S, Dunn R, van Wijngaarden P, Taylor HR, Dirani M. Sampling methodology and site selection in the National Eye Health Survey (NEHS): an Australian populationbased prevalence study. Clinical \& experimental ophthalmology. 2016.

18. Foreman J, Keel S, van Wijngaarden P, Taylor HR, Dirani M. Recruitment and Testing Protocol in the National Eye Health Survey: A Population-Based Eye Study in Australia. Ophthalmic Epidemiol. 2017;1-11.

19. Taylor HR, Keeffe JE, Vu HT, Wang JJ, Rochtchina E, Pezzullo ML, et al. Vision loss in Australia. Med J Aust. 2005;182:565-8.

20. Taylor HR, Xie J, Fox S, Dunn RA, Arnold AL, Keeffe JE. The prevalence and causes of vision loss in Indigenous Australians: the National Indigenous Eye Health Survey. Med J Aust. 2010;192:312-8.

21. AIHW. Admitted patient care 2015-16: Australian hospital statistics. Health services series no.75. Cat. no. HSE 185. In: AIHW C, editor. 2017.

22. Foreman J, Xie J, Keel S, van Wijngaarden P, Crowston J, Taylor $\mathrm{HR}$, et al. Cataract surgery coverage rates for Indigenous and nonIndigenous Australians: the National Eye Health Survey. Med J Aust. 2017;207:256-61.

23. Foreman J, Xie J, Keel S, Taylor HR, Dirani M. Utilisation of eye health care services in Australia: the National Eye Health Survey. Clinical \& experimental ophthalmology. 2017.

24. Carey RN, Glass DC, Peters S, Reid A, Benke G, Driscoll TR, et al. Occupational exposure to solar radiation in Australia: who is exposed and what protection do they use? Aust N Z J Public Health. 2014;38:54-9.

25. AIHW. 2010 National Drug Strategy Household Survey: survey report. In: AIHW, editor. http://www.aihw.gov.au/publicationdetail $/$ id $=32212254712 \&$ libID $=32212254712 \& \operatorname{tab}=22011$.
26. Chang JR, Koo E, Agron E, Hallak J, Clemons T, Azar D, et al. Risk factors associated with incident cataracts and cataract surgery in the Age-related Eye Disease Study (AREDS): AREDS report number 32. Ophthalmology. 2011;118:2113-9.

27. Hiller R, Sperduto RD, Ederer F. Epidemiologic associations with nuclear, cortical, and posterior subcapsular cataracts. Am J Epidemiol. 1986;124:916-25.

28. Rabiu MM. Cataract blindness and barriers to uptake of cataract surgery in a rural community of northern Nigeria. Br J Ophthalmol. 2001;85:776-80.

29. Marmot M. The influence of income on health: views of an epidemiologist. Health affairs (Project Hope). 2002;21:31-46.

30. Taylor HR, Henderson TR, Le Mesurier RT. Cataract surgical blitzes: an Australian anachronism. Med J Aust. 2015;202:407-8.

31. Wearne SM. Remote Indigenous Australians with cataracts: they are blind and still can't see. Med J Aust. 2007;187:353-6.

32. AIHW. Indigenous Eye Health Measures 2017 https://www.aihw. gov.au/reports/indigenous-australians/indigenous-eye-health-mea sures-2017/contents/treatment-services/3-6-2-cataract-surgery-wa iting-times-days 2018

33. Tapp RJ, Anjou MD, Boudville AI, Taylor HR. The roadmap to close the gap for vision--diabetes-related eye care in the Indigenous Australian population. Diabet Med. 2013;30:1145-6.

34. Turner AW, Xie J, Arnold AL, Dunn RA, Taylor HR. Eye health service access and utilization in the National Indigenous Eye Health Survey. Clin Experiment Ophthalmol. 2011;39:598-603.

35. Taylor HR, Boudville AI, Anjou MD. The roadmap to close the gap for vision. Med J Aust. 2012;197:613-5.

36. Biddle N. Indigenous population project: 2011 census papers. Canberra: Centre for Aboriginal Economic Policy 2012. http://caepr. cass.anu.edu.au/sites/default/files/caepr/cck_indigenous_outcomes/ 2013/11/2011CensusPaper_14_Population_Projections.pdf

37. Ferraro JG, Pollard T, Muller A, Lamoureux EL, Taylor HR. Detecting cataract causing visual impairment using a nonmydriatic fundus camera. Am J Ophthalmol. 2005;139:725-6. 